\title{
Report of the British Broadcasting Committee.
}

THE Committee appointed by the PostmasterGeneral on April 24 last to consider the present position of broadcasting in Great Britain and make recommendations for the future, made its report to him on August 23; the document (Cmd. I95I, H.M. Stationery Office, price $9 d$. net) was issued to the public on October $\mathbf{r}$.

By the terms of reference, the Committee had to consider : (a) Broadcasting in all its aspects ; $(b)$ the contracts and licences which have been or may be granted; (c) the action which should be taken upon the determination of the existing licence of the Broadcasting Company ; $(d)$ uses to which broadcasting may be put; and $(e)$ the restrictions which may need to be placed upon its user or development.

The Report, which is admirably drawn up, has been signed by all the members of the Committee; reservations are, however, made on a few points by three of them. There is every evidence that very careful consideration has been given by the Committee to the many matters associated with the present-day broadcasting problem; and certain important recommendations are made in its Report. The task of the Committee has been one of peculiar difficulty, owing to the existence of a licence from the Post Office to the British Broadcasting Company for the operation of a scheme which, while still having some eighteen months to run, has in certain respects broken down in practice. The Committee has wisely decided to disregard to a great extent this complication and has dealt with the situation practically as though the Government had a free hand.

In view of the possibility that all large communities may eventually demand this inexpensive service, and that Imperial and international broadcasting services may eventually be established, the Committee considers that "the control of such a potential power over public opinion and the life of the nation ought to remain with the State, and that the operation of so important a national service ought not to be allowed to become an unrestricted commercial monopoly." It is further pointed out that a technical reason for such control also exists: all wireless telegraphy and telephony has to be conducted within a limited group of " wave-lengths," and every new wireless station takes up a certain "waveband," which no other sending station within a certain radius should be permitted to use. These "wavebands" must, the Committee considers, be regarded as a valuable form of public property, and the right to use them for any particular purpose should be authorised only after careful consideration and in such a way that the public interest may at all times be fully safeguarded.

The Committee recognises that broadcasting is still in its infancy and that new applications of it are likely to arise from time to time in many directions. It is of opinion that, if conducted on proper and sound lines, broadcasting will be of great educative value, both directly and indirectly, and it has been much impressed with the widespread enthusiasm which broadcasting has aroused. The great interest in wireless telegraphy and telephony promoted by broadcasting in almost every class of society cannot but tend, the Committee foresees, to produce beneficial results, stimulating as it does experiment and research. "The listener," the Report says, "may perhaps become an experimenter; the experimenter may possibly become an inventor."

The Report deals briefly with the events which led to the appointment of the Committee and gives an outline of the present scheme, its merits and defects being set out. The Committee places on record the fact that the evidence placed before it " demonstrates that the British Broadcasting Company have shown enterprise and ability of a high order in carrying out their undertaking and have done much valuable pioneer work in the face of many difficulties." The Report also comments upon the objections which have been raised by certain manufacturers and dealers to the present scheme. The Committee expresses the following opinions thereon. It agrees with the view that it is wrong in principle to attempt to control the manufacture and importation of wireless apparatus by means of licences issued by the PostmasterGeneral. As regards the remaining objections, it agrees that the scheme gives the British Broadcasting Company unusual powers; the Committee, however, has had no proof that the Company has made any improper use of its position. The scheme for levying a contribution on apparatus from the manufacturers was, the Committee points out, imposed by the Government as a condition of the broadcasting licence which the manufacturers desired.

The first of the recommendations contained in the Report relates to a matter affecting the Controlling Authority. The Committee considers that the questions involved in broadcasting are so complex, and the decisions to be taken so various and require so much technical and other consideration, that a Standing Committee (unpaid) should be set up by Statute to assist the Postmaster-General in the administration -technical, operative and general-of broadcasting. It is recommended that this Committee, for which the name " Broadcasting Board " is suggested, should be composed of an independent chairman, preferably a specially qualified member of the House of Commons, nominated by the Postmaster-General, and twelve members-of these two should be specially qualified persons nominated by the Postmaster-General, and the remainder should be drawn from certain interests or bodies named in the Report. In connexion with this recommendation, the Committee thinks that broadcasting may eventually become " so great a national responsibility as to demand the creation of a small paid body of experts, to whom (always subject to the Postmaster-General) its control should be entrusted."

Sir Henry Norman, a member of the Committes, makes an important reservation in relation to the composition of the proposed Board. In his opinion " a heterogeneous Board of thirteen members, giving voluntary service, eleven of them not necessarily with special knowledge of the subject and possibly without technical knowledge at all, presided over by a member of the House of Commons, who would, of course, be chosen from the political party in power, and whose tenure of office would be subject to political exigencies, would be inefficient, would carry little authority, and its proceedings would therefore be for the most part futile." Sir Henry is in favour of the appointment of a highly-qualified and well-paid Broadcast Control Board, say, of three members; that is to say, he would prefer that immediate effect should be given to that part of the Committee's Report which recommends the creation at a future date of a small paid body of experts for the control of broadcasting.

The arguments for and against the operation of the broadcasting services by the State are set out in the Report. The Committee considers that the objections to State operation of the service outweigh the advantages; at the same time, it is of opinion that no licence issued by the Postmaster-General

NO. 28 I 5 , VOL. I I 2$]$ 
should preclude the Government from using its own wireless stations for the broadcasting of such information as may be deemed desirable, subject, of course, to the ordinary broadcast programmes being interfered with as little as possible. Mr. C. Trevelyan, a member of the Committee, expresses regret that his colleagues were unable to agree to the operation of broadcasting by the Post Office. He is of opinion that a situation may easily arise in which this may be the only satisfactory possibility and gives reasons for the views he holds.

In dealing with the means of securing widespread reception with the cheaper types of receiving sets, the Committee points out that most of the existing difficulties might be avoided or reduced by the provision of a considerable number of transmitting stations of lower power than those already existing. The possibility of employing relay stations and linking them up by Post Office telephone trunk lines to main centres is also touched upon. Developments in these directions depend upon certain technical factors, and the outlay for thus dealing with the whole country would be large, both as regards the wireless stations and the land lines. Such a scheme, the Committee points out, would enable great numbers of persons to use "crystal " receivers, and it is likely the revenue from licences would be correspondingly increased. So far as future developments are concerned, the Committee thinks that the greatest latitude should be left to the Controlling Authority, and is a matter in which it would be unwise for the Committee itself to attempt to define the policy which should be adopted. A recommendation is, however, made that the licence issued to the British Broadcasting Company, which has the requisite organisation and technical and other experience, should, subject to certain variations in its terms indicated in a later part of the Report, be continued.

The alternative methods of meeting the cost of broadcasting and the several considerations that come into play are comprehensively dealt with in the Report. Having considered the evidence placed before it on the subject, the Committee has come to the conclusion that, in order to cover the cost of running its eight stations and to pay a dividend on its capital at the rate of $7 \frac{1}{2}$ per cent. per annum, the British Broadcasting Company requires a revenue of I $60,000 l$. a year-or, if allowance is to be made for future developments and improvements, not less than $250,000 l$. a year. Of the methods of raising revenue proposed, the Committee entirely rejects the one containing a proposal that the cost of broadcasting should be met wholly or partially out of public funds. With regard to the suggestion made to it that a substantial contribution towards the cost of the service should be obtained by means of a system of licensing the manufacture and sale of wireless apparatus, the Committee says that the proposal merits careful consideration, but it is unable to recommend its adoption.

In dealing with the existing method of raising revenue by means of fees collected on licences issued to owners of receiving apparatus, the Committee has had to consider the objection which has been raised in principle to a Government Department handing over public revenue collected by it to a private individual.

The Committee is of opinion that the arguments advanced against the adoption of this method of providing funds for broadcasting are based on an incorrect conception of the nature of the transaction and recommends the continuance of the present arrangement whereby revenue is collected by means of licences for receiving sets, a part of which is handed over to the British Broadcasting Company. The aim of the Post Office should, the Committee thinks, be to obtain sufficient revenue from licence fees $(a)$ to cover administrative expenses in connexion therewith with a safe margin, and $(b)$ to provide the necessary contribution to the cost of the broadcast programme. In the event of a considerable increase in the number of licences, the resulting surplus should, it is suggested, be devoted (i.) to reducing the licence fee; or (ii.) to improve the service; or (iii.) to both these purposes. As the Post Office authorities estimate that the cost in connexion with the issue of licences is unlikely to exceed $2 s .6 d$. per year per licence, an amount of $7 s .6 d$. per licence would be available, if required, to meet the cost of all broadcasting services. The total number of licences issued up to the present is about I70,000, and there are about 30,000 applications for experimental licences held in suspense, making a total of about 200,00o. It is impossible, of course, to say what is the number of unlicensed stations; it is stated in the Report that the number is probably nearer 200,000 than Ioo,ooo. The Committee is of opinion that, if a high standard of programmes is maintained, it is not unlikely that within a few years the number of broadcast listeners may rise to a million or more. In view of the possibility of a very considerable increase in the number of licences, the Committee suggests that under any new arrangement a sliding scale should be adopted in relation to the proportion of the licence fees to be paid to the operating company or companies.

The Committee recommends that the marking of apparatus should be abandoned and one uniform licence introduced for broadcast reception and another for experimental work. It is further recommended that the broadcast licence should be placed on sale at Post Offices and issued on payment of the fee without any formalities or questions. It is pointed out that the Post Office would thereby be relieved of the difficult and somewhat invidious duty of determining whether applicants are genuine experimenters or not. With a view, however, of safeguarding neighbouring installations from interference, it is recommended that a clause should be inserted in the new licence in the following terms:-"The station shall not be used in such a manner as to cause interference with the working of other stations. In particular, back-coupling must not be used to such an extent as to energise any neighbouring aerial." Disregard of this condition should, it is suggested, render a licence liable to summary cancellation, and, further, that provision should be made for levying a penalty in cases where a licensee can be proved to have repeatedly caused serious interference. It is also suggested that for purposes of meeting cases where persons set up and use unlicensed receiving stations, statutory powers should be obtained similar to those already possessed by the Customs and Excise Department in connexion with the licences they control, so as to place the Postmaster-General in a position (a) to call upon suspected persons to fill in a form of declaration showing whether they are liable to a licence fee or not; and (b) to accept a compromise fine in the case of a minor default as an alternative to prosecution.

Having regard to the existing agreement between the Post Office and the British Broadcasting Company, the Committee recognises that it would not be possible for the Postmaster-General to introduce any change in the present scheme whereby the rights of the Company would be adversely affected, except as a matter of negotiation between the parties thereto. It is of opinion that the immediate adoption of its

NO. 28 I 5 , VOL. I I 2$]$ 
recommendations as a whole would entail certain adverse effects on the British Broadcasting Company and its constituent members. In consequence, the Committee suggests that if its recommendations are carried out forthwith, the proportion of the licence fee to be paid to the Company should be increased from $5 s$. to $7 s$. $6 d$. per licence, subject to the application of the sliding scale already referred to; this $7 s .6 d$. rate to take effect from November $\mathrm{x}, \mathrm{I922}$, when broadcast receiving licences were introduced. It is further recommended that the period of the Company's revised licence should be extended for two years beyond the original term, i.e. to January $\mathrm{I}$, 1927. It is proposed that in return for these concessions the Company, on its part, shall agree $(a)$ to the immediate application of the scheme recommended ; $(b)$ to the revision of its articles of association, in order to provide (I) for dealers and retailers of wireless apparatus to obtain at least one $\mathrm{r} l$. share in the Company, (2) for members of the public to take up shares, if and when fresh issue of capital is made, and (3) for securing adequate representation on the Board by the new membership; and $(c)$ to the abolition of the deposit of $5 \mathrm{ol}$. now required from members.

Mr. J. C. W. Reith (the General Manager of the British Broadcasting Company), a member of the Committee, makes a reservation as to the conditions proposed in relation to the issue of uniform licences and as to the general application of the scheme recommended; he is of opinion that under the proposed scheme the interests of the British manufacturers will not be sufficiently safeguarded.

On the technical side, the Committee makes certain important recommendations as to wave-lengths and the hours during which broadcasting services may be provided. It considers that arrangements should be made for the greatest possible extension of the existing broadcast band of wave-lengths ( 350 to 425 metres), preferably by the.allocation of a band from 300 to 500 metres, excluding 440 to 460 metres, and that all possible steps should be taken to protect the band allocated to broadcasting from interference by other services. The Committee further suggests that the present restrictions on the hours of broadcasting should be removed, so that additional broadcasting facilities might be provided. These changes, it is considered, can be readily introduced without detriment to the other interests which have to be considered.

In relation to the broadcasting programmes, the Committee states that the British Broadcasting Company has achieved a large measure of success in gauging the public taste and providing programmes, and suggests that there should be a gradual extension of broadcasting of news, under proper safeguards; it is also urged that more latitude should be given to the broadcasting of special events without regard to hours. Finally, the Committee places on record its conviction that the Postmaster-General should remain the final arbiter when any question is raised as to what kind of matter may or may not be broadcasted.

Contemporaneously with the issue to the public of the Report of the Broadcasting Committee, a statement was sent to the Press by the Post Office therein it is announced that the Postmaster-General feels that it is not possible for the scheme recommended by the Committee to be brought fully into operation immediately, but, with the view of the continuance of the broadcasting services, he has agreed with the Company to the introduction of a constructor's licence at a fee of $15 s$. for a limited period-the licensee must in such cases give an

NO. 28 I 5 , VOL. I I 2$]$ undertaking that, in constructing his apparatus, he will not knowingly use parts manufactured elsewhere than in Great Britain or Northern Ireland. Further, with the view of meeting the case of the 200,000 persons who are supposed to be in possession of unlicensed receiving apparatus, it is proposed to issue a special interim licence at a fee of I $_{5} \mathrm{~s}$. also, covering present apparatus, whether home-made or purchased and irrespective of its place of manufacture, provided that this licence is taken out before October I5. In such cases no charge will be made for past usage, nor will proceedings be instituted for the failure to comply with the law. The issue of the constructor's and the interim licences will be continued until December 3I, I924, and, subject to sanction by the House of Commons, the PostmasterGeneral agrees to pay $x 2 s .6 d$. and $7 s .6 d$. out of the I5s. and Ios. broadcasting licences respectively to the British Broadcasting Company. The decision of the Postmaster-General to raise the licence fee to the home-constructor has come as a real disappointment to a very large number of them : to many of this class of listener the increase of the fee from Ios.

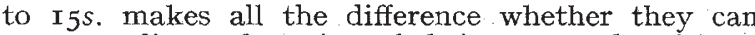
possess a licensed station of their own or do without one altogether.

An agreement has also been come to between the Post Office and the British Broadcasting Company for the modification. of the articles of association of the Company on the lines recommended by the Committee. The licence now held by the Company will be prolonged, on suitable conditions, to the end of 1926 ; provided that the Company gives a satisfactory service and is willing to erect additional stations, should the Postmaster-General require this to be done, it is given what is virtually a monopoly during the unexpired period of the original agreement. However, the rights of the Postmaster-General are reserved, in certain circumstances, from and after December 3I, I924; thereafter not only may he, in appropriate cases, license other organisations, but he may also give them an adequate share of the revenue arising from new licences. The PostmasterGeneral may further (without regard to geographical area) license other services without withdrawing any part of the licence fees to which the Company may be entitled.

It is announced also that the Postmaster-General proposes at an early date to appoint an Advisory Board, as recommended by the Committee, to assist him in all important questions relating to broadcasting. Presumably this Board will be a statutory body: whatever may be the sources from which its membership is drawn, it is to be hoped that every care will be taken to avoid the creation of the inefficient type of Board so strongly condemned, and justly so, by Sir Henry Norman in the special paragraph contributed to the Report by him.

The action taken by the Postmaster-General on the Report of the Broadcasting Committee brings to a close the deadlock which has now for some months existed between the Post Office and the British Broadcasting Company. It is somewhat unfortunate that the restoration of peace between the parties to the original agreement has been purchased at the expense of a class, the home-constructors, who are deserving of greater consideration than they are about to receive. It is not at all improbable that the course of events may cause both the PostmasterGeneral and the British Broadcasting Company to regret that the recommendations of the Broadcasting Committee in relation to the introduction of one uniform broadcast licence have not been at once put into force. 